\title{
Research on the application of computer technology in university administrative supervision
}

\author{
${\text { Pan } \text { yihui }^{1,} \text { a }, \text { Wang Guangqing }}^{1, b}$, Tu Keqing ${ }^{2, c}$ \\ ${ }^{1}$ Jiangxi Science \& Technology Normal University, Nanchang, Jiangxi, 330013, P.R. China \\ ${ }^{2}$ Nanchang City Taohua School, Nanchang, Jiangxi, 330025, P.R. China \\ ancpanyihui@126.com, b wanggq005@163.com, ${ }^{\mathrm{c}}$ nctkq@126.com
}

Keywords: Computer, University, Administrative supervision

\begin{abstract}
With the continuous deepening of the reform of higher education in China and the continuous expansion of the scale of higher education, the number of administrative departments in Colleges and universities has greatly increased. In order to improve the working enthusiasm and working efficiency of the administrative staff, the administrative supervision departments have been set up in order to explore and establish the teaching quality guarantee and monitoring system. The computer technology is one of the most great inventions in twentieth Century. The computer technology is applied to the administrative supervision in Colleges and universities. It can provide the working efficiency and reduce the error in the administrative supervision.
\end{abstract}

\section{Introduction}

At present, with the development of higher education in our country, the number of students has increased greatly, and the number of people in the administration has also increased significantly. In order to improve the work efficiency of university administrative staff and make it better for the teaching service, the administrative supervision departments are set up in every university. Because of the differences in the orientation, the idea of running school, the scale of running school, and the situation of the school, the administrative supervision in Colleges and universities are complex and diversified. From the concept of the steering to the working mechanism, from the agency set up to the scope of work responsibilities and so on. Some problems in the work of administrative supervision are restricting the development of administrative supervision. Applying computer technology to administrative supervision, can effectively improve the efficiency of the administrative supervision work.

\section{The problems in the work of administrative supervision}

There are many problems in the actual work of administrative supervision in Colleges and universities to carry out, such as supervision is often to "Doc" less than "guide", affect the overall quality of the executive team; supervision of some administrative tendency, resulting in some not harmonious; supervision work often adopts the stylized model, the evaluation of administrative staff is not comprehensive enough, some advantages of the even obliterated the administrative staff of the; administrative supervision work to carry out in the process of human factors are more; the efficiency of the administrative supervision is relatively low, and so on.

The steering team is not sound, it is difficult to play a supervisory role. According to the in-depth interviews and with their own understanding and analysis of some colleges and universities, the overall view, the composition of the University's administrative supervision team and personnel appointment standards, there is a greater randomness.

Here are some of the interviews:

Visitor: how many staff members are there in the steering room? Is it full time or part time? 
Respondent: school inspection is divided into two parts, a part is full-time staff in the post, people, organizations to carry out the work of administrative supervision; another part is the external school staff, mainly is the old experts, responsible for the first-line supervision and evaluation work.

Visitor: how about the degree and age of the supervisor?

Respondents: most of the staff are outside the retired leadership, or school leadership, the average age of 60 years or so.

Visitor: is there a formal hiring process for staff appointments?

Respondents: no formal employment system, can only be based on the supervision of the title and work experience decision.

The visitor experience: whether pre job training before work?

Respondents: without the experience of training, we can only independent learning related policies, or read some documents

From the above statement can be seen, the current domestic university administrative supervision organization, most of the old fanpin led by the school and finally retired and serving officers together, although retired old leadership has very rich management experience and time, but in the current state of higher education enrollment, the scale has been expanding in the background, there will be changing all the new ideas and ways of thinking of the phenomenon, then the concept and way this time some retired leaders still remain stagnant, will inevitably have some differences with young people and students, carry out supervision and guidance work in this unified educational ideology, sometimes will also cause some students and young people antipathy. Therefore, how to employ the supervision personnel, how to improve the quality of the supervisors, how to coordinate the proportion of retirement and service to become the problem to be discussed in the steering group.

It is difficult to achieve a fair evaluation of the subjective will of the steering standards. At present, many colleges and universities in the teaching supervision work in the process of teaching and learning in the classroom teaching quality, it is clear that this is a way to check the role, and can not improve the quality of teaching, and simply by listening to the evaluation of teachers' teaching ability is not fair. When the supervisor to attend a lecture, often to the teacher and the students bring tension, some teachers also have a kind of conflict. Teaching supervision personnel age larger, in supervision because of the physical and emotional effects of loose, no plan, no standard that free lectures, conflicts, and ultimately affect the improvement of teaching quality. Therefore, in addition to improving the teaching supervision, there should be a scientific and reasonable evaluation criteria, only to make the supervision personnel in accordance with the clear criteria to assess, will not lead to the subjective awareness of the components in the course of the supervision is too heavy, but also to the objective and scientific evaluation of teaching quality. However, at present, many colleges and universities do not have such a clear standard, to a large extent, weaken the correctness and authority of the supervision work.

The feedback form is single, and it is difficult to achieve the goal of supervision. The goal of administrative supervision is to supervise and improve the administrative efficiency of the University. It seems that the feedback is still in a single state. The feedback system is too simple and the efficiency is low. From the feedback content, the administrative supervision is mostly for the contents of the inspection to the staff, but it is often one-sided. So we should establish a kind of feedback method to solve the problems in Colleges and universities.

\section{The application of computer technology in university administrative supervision work}

Since 1946, the first electronic computer ENIAC in since the birth of the University of Pennsylvania in the United States, has only a short period of sixty years, computer technology has been rapid development. Especially since twenty-first Century, with the development of network technology and micro electronic technology, the computer's volume is getting smaller and smaller, more and more powerful, it can be said that the application of computer technology has penetrated every field of social life, so that our life has been greatly changed. The application of computer 
technology to the administrative supervision in Colleges and universities can effectively solve some problems and improve the working efficiency of the administrative supervision.

The supervision of the staff of the use of computer technology to strengthen their own learning, improve their own quality. From the foregoing, we can know that how to improve the quality of supervisors is a problem faced by the current supervision. Send them out training, will be subject to many conditions. However, now that computer technology is very developed, we can make supervision staff to use the computer, via the Internet, distance learning new knowledge and ideas; different colleges and universities of supervisory staff can also use a computer, via the Internet, strengthen exchanges, learn from each other, so as to improve their own quality, improve the quality of the supervision team.

The use of computer technology in the supervision of the work to improve the impartiality and objectivity. In the present evaluation mechanism, one of them is the mutual evaluation between interviews and colleagues. Colleagues often because of the sensibilities, not fair to the evaluation object evaluation. In favor of the computer to carry out interviews and mutual evaluation, the colleagues are no longer in the face, to improve the evaluation of the fairness and objectivity.

For the computer to carry out feedback. After the evaluation of the work of the staff, the evaluation results should be evaluated to the evaluation object. In the facing surface of the feedback and supervision because of the sensibilities and some descriptions often evasive, evaluation objects are some of the disadvantages of the understatement of the band before and its advantages were amplified. In fact, it is not conducive to the growth of staff and improve the efficiency of staff. If you can help the computer to feedback, you can very good customer service these shortcomings. Can be the evaluation results into the steering database, only the evaluation object I can see, so that is conducive to the evaluation of the object to understand their own shortcomings, improve the efficiency of the work.

\section{Conclusion}

To continuously improve the supervision of the content and methods, to avoid the use of mandatory or administrative orders to solve the problem of staff in the work process. To fully understand and respect the administrative staff, the use of some of the human nature of the work mode and technology, to abandon some of the administrative practices. Only in this way can the maximum extent be close to the grass-roots staff, so that the majority of staff support, with the supervision work.

\section{References}

[1] C.D. Fu. The innovation of teaching supervision in Colleges and universities. Guangxi Social Sciences, 2008, (7).

[2] X.H. Duan, J.H. Wang. Research on the teaching supervision system and operating mechanism of higher education institutions. Chinese university teaching, 2005, (10).

[3] C.Y. Wang, J.H. Zhang, J.D. Wang. New thinking of university teaching under the new situation. Journal of Hebei Normal University: Education Science Edition, 2008, (10).

[4] H.Y. Ma, L.D. Li. The development of College Teaching Supervision in the new period of several. trend of modern education, 2008, (1).

[5] Z.F. Zeng, Dong, Xiao Qin Zong, bell Xuhui. In order to build a harmonious campus as the main innovation of college teaching supervision mechanism. Yearbook of the world Chinese Entrepreneurs: higher education research, 2009. (8). 